\title{
Studies on the Development of Surgical Renal Tuberculosis
}

\author{
By \\ Yoshito Yaoita \\ ( 矢尼板莪人) \\ From Prof. M. Muto's Surgical Clinic, Faculty of Medicine, \\ Tohoku University, Sendai
}

(Received for publication, September 14, 1953)

It has been well established by Wegelin-Wildbolz, ${ }^{11}$ Koike, ${ }^{2)}$ and others that surgical renal tuberculosis begins at the papilla-calyx area. Though the process of appearance of this primary lesion at the papillacalyx area was not clear at first, it has recently been generally accepted among American and British workers, dating back to the work of Medlar, ${ }^{31}$ that (1) tubercles are formed first in the cortex by tubercle bacilli carried by the blood stream to the kidney; (2) these early tubercles have a strong tendency to heal to scars, thus usually becoming harmless; (3) but if a tubercle continues to grow under certain circumstances and breaks into a renal tubucle, the discharged bacilli descend along the tubule to the papilla-calyx area, where they give rise to the formation of a lesion, surgical tuberculosis being thus developed (Lieberthal, ${ }^{4)}$ Band, ${ }^{5)}$ Lowsley and Kirwin, $\left.{ }^{6)}{ }^{\text {Dukes }}{ }^{7}\right)$. This hypothesis is based upon the results of studies by Harris ${ }^{8}$ and others on tuberculous bacilluria of patients with renal tuberculosis at sanatoriums and upon those obtained by Medlar and his school $\left.{ }^{9}\right)$ from experiments on laboratory animals and from histological studies of kidneys of patients dying of renal tuberculosis. It is difficult to verify this hypothesis by histologic examination of operative removed kidneys of patients with surgical renal tuberculosis. If, however, out of many clinically excised tuberculous kidneys are selected those specimens in which the lesions are only localized and the remaining relatively " normal" areas are large, and then the latter " normal " areas are examined by the serial section method, it might be possible to obtain findings that afford some basis for this hypothesis. In view of this posibility, careful microscopical examination of serial sections was made upon relatively normal areas of three such specimens of kidney, with the results to be reported in the present paper.

\section{Material and Method}

Case 1. A 25 year old male with left renal tuberculosis. One cut 
surfaces there was observed a caseous papillary lesion, $0.7 \times 0.5 \mathrm{~cm}$., on a middle minor calyx. On the contiguous mucosa of the pelvis, tubercles and a tuberculous ulcer were found in a small area. Macroscopically, other pelvis as well as major and minor calyces were nearly normal, there being detected subepithelial tubercle formation on a few lower calyces only microscopically. In the remaining renal parenchyma, only a few tubercles were found macroscopically. The whole kidney was divided into 73 blocks and a total of 31,322 sections were prepared.

Case 2. A 16 year old male with left renal tuberculosis. On the upper pole of the kidney there was observed a caseous papillary lesion, $0.6 \times 0.6 \mathrm{~cm}$.; no remarkable changes were found in the remaining renal parenchyma. The mucosae of upper major calyces were caseous over the whole surface; the upper half of the pelvis mucosa was affected by tuberculous ulceration, while no macroscopic changes were perceived on the mucosa of lower major calyces. The whole kidney was divided into 71 blocks, and a total of over 5,000 sections were prepared for closer examinations of relatively normal parts of the lower half of the kidney.

Case 3. A 32 year old female, with left renal tuberculosis. The tuberculous lesions were found to be more advanced than in the above two specimens. There were observed a cavitation, $1.5 \times 1.2 \mathrm{~cm}$., on the lower pole of the kidney, and remarkable tuberculous lesions over the whole surface of the lower half of the pelvis mucous membrane. Minor calyces situated above an upper major calyx showed a thickening due to a stricture at the cervical part of the latter, but no marked tuberculous lesions were observed. A total of over 4,000 sections were prepared for closer examinations of the relatively normal upper part of the kidney. A small number of sections were prepared also from several areas of the middle and lower portions of the kidney.

Staining of the secitons. Most of the sections thus prepared from the three kidney specimens were stained with hematoxylin and eosin. The remaining small number of sections were treated with Van Gieson's stain, Mallory's stain, Weigert's stain for elastic fibers, a stain for tubercle bacilli, or Bielschowsky's silver method.

\section{Results}

Results of examinations in Case 1.

1) The middle papilla-calyx area bearing the major lesion. The caseous lesion affected almost all the papillae and medulla and extended as far as the corticomedullary zone and medulla, being surrounded by tuberculous granulation tissue containing a large number of tubercles. From this lesion, restiform lesions being produced by round cell infiltration and sometimes accompanying a tubercle formation extended radially to 
the surface of the kidney (Fig. 1). These changes were restricted to the

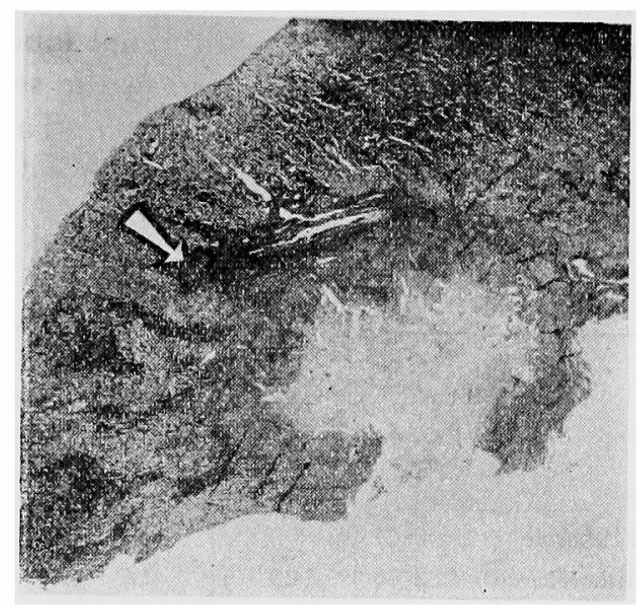

Fig. 1. Restiform lesions extending radially from a caseous lesion to the surface of the kidney. A tubercle is shown by the arrow.

renal lobe belonging to the affected papilla, there existing in the medulla and cortex 86 conglomerate tubercles of about $1 \mathrm{~cm}$. in diameter (Fig. 2) and still more abundant "smallest giant cell tubercles" to be described later. Almost all these tubercles seem to have ensued pyelonephritically

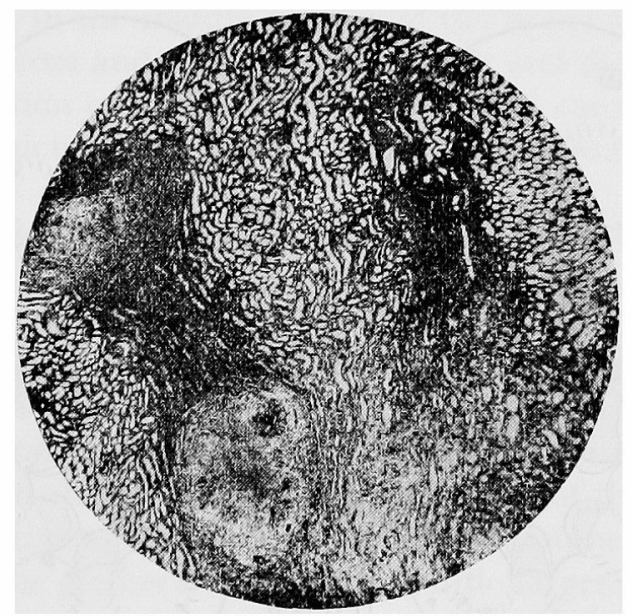

Fig. 2. Conglomerate tubercles in restiform lesions.

from the caseous lesion, but whether there were mixed among them hematogenous tubercles that had become the origin of the caseous papillary lesion according to Medlar's hypothesis was not clear, due to the presence 
of too large a number of tubercles there.

b) Lesions in the renal parenchyma of the relatively normal area. Macroscopically, the portions other than the renal lobe having the main lesion appeared nearly normal. Examination of the serial sections, however, revealed 58 tuberculous nodules in the latter (Table I and Fig. 3).

\section{TABLE I}

Tuberculous Nodules in the Relatively "Normal" Area of the Kidney

\begin{tabular}{|c|c|c|c|c|c|c|c|}
\hline & \multirow[b]{2}{*}{ Lesion } & \multicolumn{3}{|c|}{ Cortex } & \multirow[b]{2}{*}{$\begin{array}{l}\text { Renal } \\
\text { column }\end{array}$} & \multirow[b]{2}{*}{$\begin{array}{l}\text { Renal } \\
\text { sinus }\end{array}$} & \multirow[b]{2}{*}{ Total } \\
\hline & & $\begin{array}{l}\text { Renal } \\
\text { surface }\end{array}$ & $\begin{array}{l}\text { Inter- } \\
\text { mediate } \\
\text { resion }\end{array}$ & $\begin{array}{c}\text { Cortico- } \\
\text { medullary } \\
\text { zone }\end{array}$ & & & \\
\hline \multirow{3}{*}{ Case 1} & Epithelioid tubercle & 0 & 2 & 0 & 0 & 0 & 2 \\
\hline & Giant cell tubercle & 2 & 23 & 22 & 3 & 2 & 52 \\
\hline & $\begin{array}{l}\text { Extinct conglomer- } \\
\text { ate lesion }\end{array}$ & 1 & 2 & 1 & 0 & 0 & 4 \\
\hline \multirow{2}{*}{ Case 2} & Epithelioid tubercle & 0 & 6 & 1 & 0 & 0 & 7 \\
\hline & Giant cell tubercle & 3 & 0 & 0 & 0 & 0 & 3 \\
\hline Case 3 & Epithelioid tubercle & 2 & 1 & 0 & 0 & 0 & 3 \\
\hline \multicolumn{2}{|r|}{ Total } & 8 & 34 & 24 & 3 & 2 & 71 \\
\hline
\end{tabular}

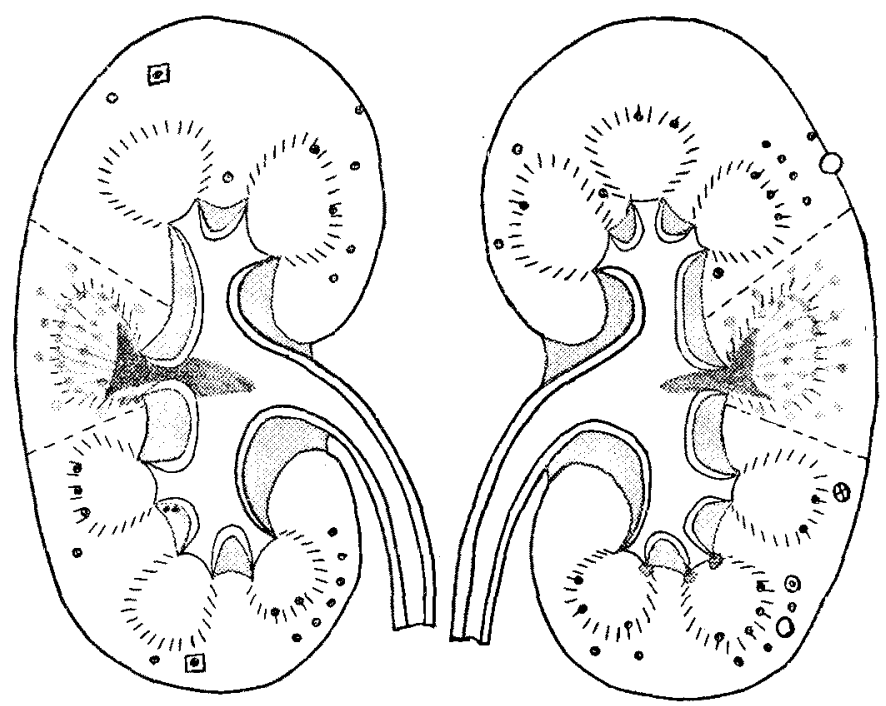

Fig. 3. The distribution of tuberculous lesions in Case 1. $\oplus$, 1st conglomerate lesion. $\odot$, 2nd conglomerate lesion. $\bigcirc$, 3rd and 4th conglomerate lesions. Smallest tubercles. [., Epithelioid cell tubercles. 


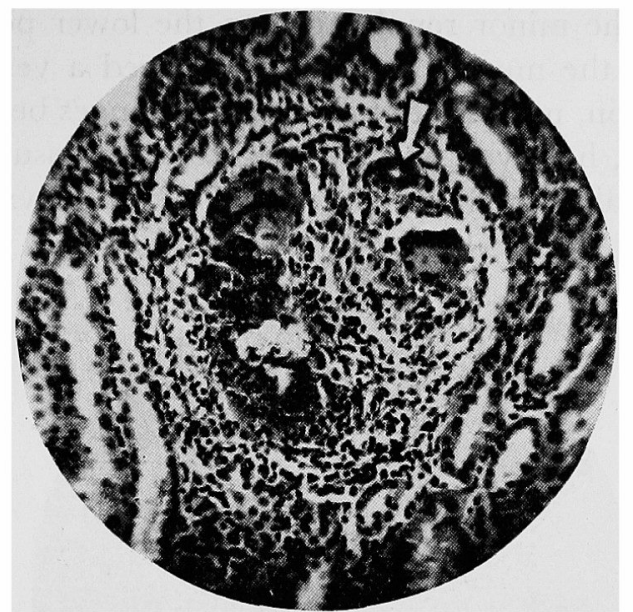

Fig. 4. The smallest giant cell tubercle. The arrow indicates a tubule.

A large majority (52) of these nodules consisted of one to four giant cells (Fig. 4), a few epithelioid cells and fibroblasts, and were surrounded by a layer of lymphocytes. They were of the order of magnitude of a glomerulus or smaller and will be referred to as "smallest giant cell tubercles" in this paper. There were found only two "epithelioid cell tubercules", i.e. those smallest tubercles which were similar to the above but not found to contain giant cells upon examination of the serial sections. One of them was situated in the middle portion of the upper renal cortex, where both the calyx mucosa and papillae were intact; and the other was situated in the middle portion of the cortex, where a small caseous lseion was seen at a lower calyx niche; both these tubercles were situated apart from the glomerulus.

The distribution of these 52 smallest giant cell tubercles is shown in Table I, where it will be seen that only two tubercles were present in the renal sinus, while the remaining 50 were all found in the cortex or the renal columns. As for the relation of these 52 tubercles with the glomerulus, each of 18 tubercles laid close to a glomerulus or with the surrounding lymphocytes infiltrating into the glomerulus, and the remaining 32 were found isolated from the glomerulus. The smallest of these tubercles were all formed interstitially; the smallest ones lightly pushed the renal tubule and occasionally the glomerulus, while in a little larger ones the surrounding round cell infiltration extended as far as the renal tubule and glomerulus, but there was found no case in which a tubercle broke into these tubules or involved the glomerulus.

The two smallest giant cell tubercles as seen in the renal sinus were the ones that had been formed side by side in the same area contiguou $_{\mathrm{S}}$ 
to the mucosa of the minor renal calyx on the lower pole of the kidney. On this portion of the mucosa there was observed a very slight extent of round cell infiltration, no definite tuberculous changes being demonstrated.

These changes, however, are regarded to have ensued from the calyx mucosa, for tuberculous nodules were found at the calyx niche of the adjacent papilla (Fig. 5).

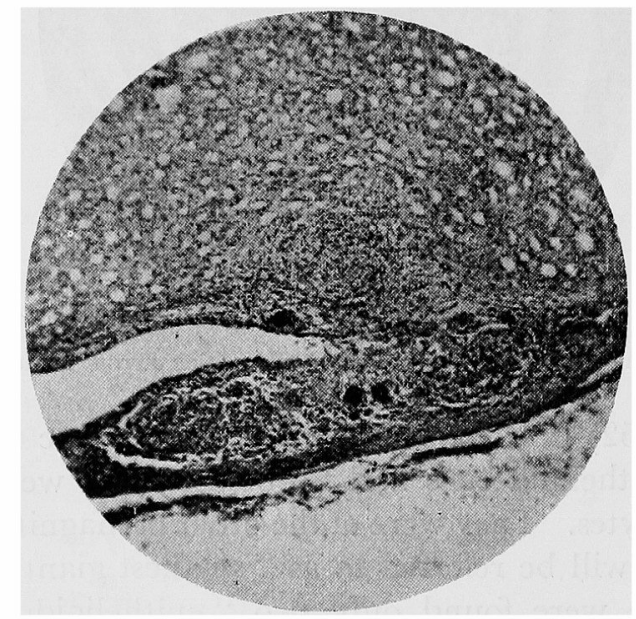

Fig. 5. A tuberculous lesion at a lower calyx niche found in Case 1.

All the smallest giant cell tubercles as found in the renal columns were situated on the upper pole of the kidney. No tuberculous lesion was detected on the mucosae of the major and minor calyces of this portion. Of the 47 cortex smallest giant cell tubercles, two were formed in close proximity to the renal surface, 22 in the cortex at the corticomedullary zone, and 23 in the central portion of the cortex, solitarily at places other than the renal lobe belonging to the main lesion in the middle part of the kidney. No tuberculous lesions were revealed on the minor renal calyces, mucosae, and papillae in all the portions of the kidney, with an exception of a part of the lower pole, nor were pyelonephritic lesions demonstrated in the area between the tubercles and the papilla-calyx area.

Besides the smallest giant cell tubercles mentioned above, there were found four relatively large tubercles, more than ten times as large as the glomerulus. The findings common to these tubercles were that they were much larger than the smallest giant cell tubercles, and that there was found a remarkable proliferation of the connective tissue fibers.

The first conglomerate lesion of tubercles extended from the corticomedullary zone of the lobe adjacent to the lobe having the main lesion to the middle portion of the cortex, and the papilla in this portion was 
intact. The central part of this conglomerate lesion of tubercles consisted mainly of epithelioid cells and connective tissue fibers. This was surrounded first by the smallest tubercles having giant cells, then by a layer of lymphocytes.

The second conglomerate lesion (Fig. 6) was found in the cortex of the lower part of the kidney, in which a central caseous lesion of a small area was surrounded first by connective tissue fibers, then by tuberculous granulation or by tubercles, and finfilly by a layer of lymphocytes. In this neighborhood there were seen also scarred glomeruli. The papillary area in this part corresponded to the calyx-niche lesion shown in Figure 5.

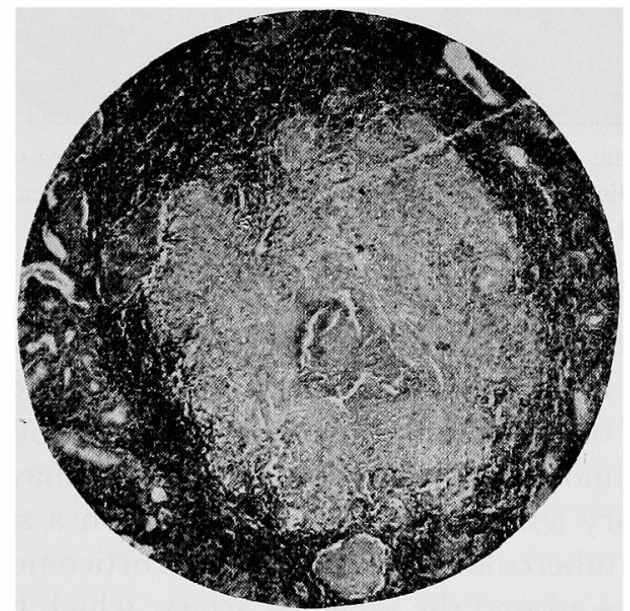

Fig. 6. The second conglomerate lesion, the central area of which shows a caseation. A proliferation of connective tissue is seen at the central area.

The third conglomerate lesion was situated in the cortex of the same lobe having the second conglomerate lesion but apart from the latter. The fourth conglomerate lesion was found on the surface of an upper renal lobe, where both the calyx and papilla were intact. The central areas of these third anfd ourth lesions were occupied mainly by connective tissue fibers showing a hyaline degeneration (Fig. 7), being surrounded by tuberculous granulation tissue and lymphocytes.

As mentioned above, the proliferation of connective tissue fibers was invisible in the smallest giant cell tuberlces but remarkable in the conglomerate lesions. In view of these facts, an examination of the degree of proliferation was made upon these fibers in the conglomerate lesions on the previously mentioned renal lobe having the main lesion, with the results that in the main lesion the proliferation was of an extent similar to that of the first conglomerate lesion, no scarring such as seen in the second to fourth lesions being observed. 


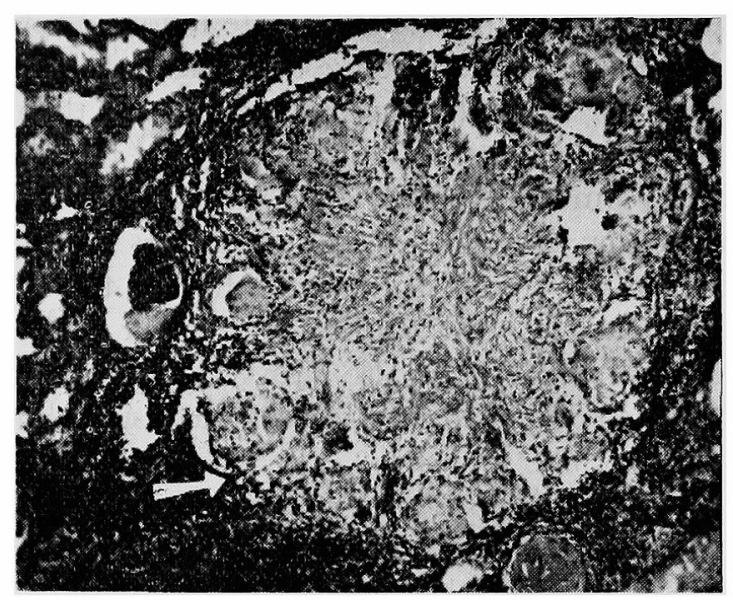

Fig. 7. The third conglomerate lesion, the central area of which is occupied by hyaline connective tissue fibers. The arrow indicates giant cells and epithelioid cells.

Results of examinations in Case 2.

The caseous lesion in the upper part of the kidney of Case 2 occupied two fused papillae and extended as far as the corticomedullary zone, and a large number of tubercles were found in the renal lobes connected with these papillae. Almost all these tubercles seem to have been ensued in the caseous papillary lesion as in Case 1. Even on a single section there were found a few tuberculous nodules in the corticomedullary zone, and several such nodules around the arciform artery, which had been produced pyelonephritically by the lesion at the calyx. Among these nodules an extinct scarred lesion was found, being surrounded by hyaline connective tissue fibers (Fig. 8). Thus, this scarred lesion also may be taken to be the oldest one that had ensued from the papillary lesion, though the possibility that this had been formed hematogenously prior to the development of the papillary lesion can not be excluded.

Though the mucosa of the lower major calyces were intact to the naked eye, microscopically a subepithelial tubercle formation was perceived on rare occasions; the papillae were intact also microscopically, but serial sections revealed six of the smallest tubercles in the cortex.

All these six tubercles were lesions mainly consisting of epithelioid cells surrounded by a layer of lymphocytes; due to a large extent of the lymphocyte infiltration the tubercles were fairly larger than the smallest giant cell tubercles in Case 1. Giant cells were found in two of these tubercles. As for the site of formation, one was formed in the corticomedullary zone, one on the renal surface, and four in the middle part of the cortex; two of the six were found close to and four apart from the 


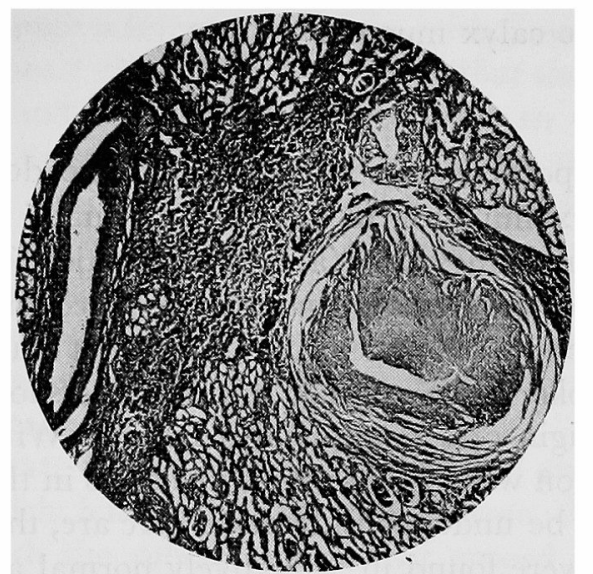

Fig. 8. A scarred lesion in the renal lobe having the main lesion (Case

2). A remarkable round cell infiltration is seen around the arciform artery.

glomerulus, being situated interstitially in all cases.

In the middle part of the kidney, that is, in the part intervening between the upper diseased and the lower relatively normal part, four smallest tubercles ( 3 epithelioid cell tubercles and 1 giant cell tubercle) of equal quality were found, one close to and three apart from the glomerulus, in the cortex of the area where a profound tuberculous lesion affected the calyx mucosa but not the papillary region; the pyelonephritic course in the formation of these tubercles were not clear, however.

Thus, in the relatively normal area in Case 2 there were found a total of 10 smallest tubercles (7 epithelioid cell tubercles and 3 giant cell tubercles), three of which were situated close to and seven apart from the glomerulus.

Results of examination in Case 3.

In the lower part of the kidney there existed a large lesion with a cavitation, more advanced than in the remaining two cases. Tuberculous changes were so profound also in each lower minor calyx that a large number of tubercles were formed in the parenchyma of the lower part of the kidney. Also in this case, these tubercles seem to have supervened in the calicine and papillary lesions.

Serial sections of the upper relatively normal area revealed three smallest tubercles consisting mainly of epithelioid cells; no giant cells were detected. Two of these were situated on the renal surface, their surrounding layer of lymphocyte infiltration being wedge-shaped and enclosing the glomerulus therein. The remaining one tubercle was found in the cortex of the corticomedullary zone, close to the glomerulus; though the papilla in this area was found normal, a subepithelial tubercle forma- 
tion was seen on the calyx mucosa.

\section{Discussion}

If Medlar's hypothesis can be applied to the development of renal tuberculosis, close examination of a large "normal " area of a surgically removed tuberculous kidney with a localized major lesion may reveal in the cortex those tubercles hematogenously produced prior to the establishment of the major lesion which healed to an extinct scarred lesion or which aggravated and broke into the renal tubule, thus showing the possibility of becoming the origin of a papilla-calyx lesion. With such an expectation close examination was made in the three cases in the present investigation. Tubercles to be under consideration here are, therefore, those tuberculous ones which were found in a relatively normal area of the kidney.

Upon close examination of a total of 31,322 serial sections prepared in Case 1, 58 solitary tuberculous lesions were detected in the relatively normal area. Most of them were minute tubercles of the order of magnitude of a glomerulus, 52 of which were giant cell tubercles, two being epithelioid cell tubercles. Examination of more than 5000 serial sections prepared from the relatively normal area in Case 2 revealed seven epithelioid cell tubercles and three giant cell tubercles, while three epithelioid cell tubercles were detected on more than 4000 serial sections of the relatively normal area in Case 3. Common to Cases 1,2 and 3, these smallest tubercles were characterized by being almost devoid of connective tissue fibers, which fact seems to indicate that these tubercles were relatively fresh.

Different from these smallest tubercles, in the four conglomerate lesions seen in the cortex of Case 1, the outermost layer consisted of lymphocytes and the middle layer had tuberculous nodules with giant cells or tuberculous granulation, while the central area consisted of proliferated connective tissue fibers and epithelioid cells in the first conglomerate lesion, of a small caseous lesion surrounded by connective tissue in the second, and solely of hyaline connective tissue in the third and fourth.

Medlar's interpretation of the tuberculous process may be summarized as follows: An epithelioid or mononuclear tubercle is first formed (the first stage of a tuberculous lesion), then an abscess is formed there (the second stage), and finally caseation supervenes and giant cells appaer (the third or reparative stage). Following caseation the mononuclear leucocytes and lymphocytes are attracted in large numbers. As a reparative process goes on toward completion the need for mononuclear leucocytes and lymphocytes becomes less and less until the product is a scar.

According to this viewpoint, the results of examination of the smallest tubercles in the above three cases may be represented as follows: In Case 1, a large majority of the tubercles were giant cell tubercles in the 
reparative stage, though a few of them were epithelioid cell tubercles in the second stage; in Cases 2 and 3 it may be taken that there were found a few tubercles in the second stage and a few tubercles in the third, reparative stage; in addition, there was observed a proliferation of connective tissue fibers at the central area of the conglomerate lesions as seen in Case 1, the extent of the proliferation being of the increasing order of the first, second, third, and fourth lesions; in particular, the central area of the third or and fourth lesion consisted solely of connective tissue fibers and might be called a scar; this scar, however, was surrounded by a tuberculous lesion in the reparative stage.

The conglomerate lesions found in the normal area in Case 1 may be taken as those which had advanced further from the repearativ sgage. Comparing this with the tubercles that had ensued in the cortex of the renal lobe having the main lesion, a proliferation of connective tissue to such an extent as that of the first conglomerate lesion in the normal area was seen, but such instances of scarred tubercles as occurred in the second to fourth conglomerate lesions were not found. If tissue reaction of the cortex is assumed to be of the same extent in various parts of a kidney, the second to fourth conglomerate lesions may be taken to be older than those lesions that had ensued in the cortex of the renal lobe having the main lesion.

The process of formation of the smallest tubercle in a normal area can be inferred in various ways. As it is strongly possible that this formation is either hematogenous in origin or due to pyelonephritic spreading, these two possibilities have to be examined here. According to Medlar, Band, and others, the earliest tuberculous lesion hematogenous in origin usually appears in relation to the glomerulus of the renal cortex or in the capillary between the collecting tubeuls in the pyramid (Medlar).

In the present investigation, the sites of tubercle formation of the smallest size in the cortex of the normal area in Cases 1 to 3 were as follows: Of the 62 tubercles, seven were found in the superficial part of the renal cortex, 23 in the corticomedullary zone, and 32 in the intermediate area; of the 65 smallest tubercles (including those found at the renal coloumns), 24 were situated close to the glomerulus, while the remaining 41 were in the interstice, apart from the glomerulus, there being found no tubercles to have been formed at the glomerulus itself. It has not been clear whether the smallest tubercles as found in the interstice of the cortex were hematogenous in origin.

It has been clearly shown by Stoerk, ${ }^{9}$ Putschar, ${ }^{10}$ ) and others that surgical tuberculosis will, when formed in the papilla-calyx area, extend pyelonephritically into the renal parenchyma, and this was confirmed by Muto, Maeda and Murai, ${ }^{1112)}$ of our Clinic. This "pyelonephritic ex- 
tension" seems to be synonymous with the "ascending reinfection of the kidney" as described by Lieberthal. According to the results obtained at our Clinic, in the renal parenchyma where the major lesion is restricted to a certain area but tuberculous pyelitis extends from this lesion, a lymphocyte infiltration will invade, though the papilla is intact, along the interlobar and arciform arteries from the calyx mucosa. Occasionally there are found tubercles at several places, which may be regarded as pyelonephritic extension.

As already mentioned, in many cases no changes were found on the papilla, minor calyx and mucosa of the lobe where tubercles had been formed. In some cases, however, a small tuberculous lesion was observed at the minor calyx niche. It has not been proved clearly that these smallest tubercles has not been proved clearly that these smallest tubercles had been formed pyelonephritically.

Thus, from the findings of the present investigation, no definite conclusion can be drawn as to whether the tubercle formation was pyelonephritic or hematogenous. However, if assumed to be hematogenous in origin, these tubercles are taken to have been formed later than the main lesion. Hence, these tubercles were possibly produced at the time of hematogenous outburst of tubercle bacilli after the main lesion had been formed. In the central areas of the second, third and fourth conglomerate lesions in Case 1 there were observed tuberculous lesions in a stage older than that of the tubercles found in the renal lobe having the main lesion. These tuberculous lesions may be regarded as the scarred tubercles formed hematogenously before the main lesion was produced, although the tubercles were not completely scarified but surrounded by tuberculous lesions in my cases.

Further, among the tuberculous lesions in the normal area, no lesion was found to have aggravated and broken into the tubules, such as found by Konno and $\mathrm{Abe}^{13}$ in the kidneys obtained upon authopsy of patients with pulmonary tuberculosis. This difference may be due to a high vividness of the surgical case as compared with the exhausted state of the cases with severe phthisis.

The hypothesis on the development of renal tuberculosis as put forward by Medlar, Lieberthal, Band and others is quite a clear-cut one. It seems difficult, however, to find its base in surgically removed kidneys.

\section{SUMMARY}

Three specimens of surgically removed tuberculous kidney with localized major lesions and with large "normal " areas of the renal parenchyma were examined by the serial section method, with the following results : 
1. In the normal renal parenchyma, that is, all the parts except the renal lobe having the main lesion, there were found 58 isolated tubercles in Case 1, 10 in Case 2, and three in Case 3. Many of these tubercles were epithelioid cell tubercles or giant cell tubercles, in no cases was a proliferation of connective tissue fibers observed.

2. A proliferation of connective tissue fibers or scarring was seen at the central areas of the third and fourth conglomerate lesions in Case 1, but tuberculous granulation was detected in their surroundings.

\section{References}

1) Wegelin \& Wildbolz, Z. urol. Chir., 1913, 2, 201.

2) Koike, Mitt. allg. Path. (Jap.), 1927, 3, 490.

3) Medlar, Amer. J. Path., 1925, 2, 401.

4) Lieberthal, Surg. Gyn. \& Obst. 1938, 67, 26.

5) Band, Brit. surg. practice, London, 1948, 5, 307.

6) Lowsley \& Kirwin, Clinical urology, Baltimore, 1944, II, 1488.

7) Dukes, Ann. Roy. Coll. Surg. England, 1948, 2, 299.

8) Harris, Brit. J. Surg., 1929, 16, 464.

9) Medlar \& Sasano, Amer. Rev. Tbc., 1924/25, 10, 371.

10) Stoerk, Handb. d. spez. path. Anat. u. Hist., Berlin, 1925, $6(\mathbf{1}), 487$.

11) Putschar, Handb. d. spez. path. Anat. u. Hist., Berlin, 1934, 6(2), 396.

12) Moto, Maeda \& Murai, Tohoku Igaku Zassi, 1946, 35, 222.

13) Muto, Nippon Rinsho Kekkaku (Jap.), 1950, 9, 513.

14) Konno \& Abe, Tohoku Igaku Zassi, 1952, 47, 1. 